\title{
Pain, activities of daily living and sport function at different time points after hip arthroscopy in patients with femoroacetabular impingement: a systematic review with meta-analysis
}

\author{
Signe Kierkegaard, ${ }^{1}$ Martin Langeskov-Christensen, ${ }^{2}$ Bent Lund, ${ }_{1}^{1}$ Florian D Naal, ${ }^{3}$ \\ Inger Mechlenburg, ${ }^{4,5}$ Ulrik Dalgas, $^{2}$ Nicola C Casartelli ${ }^{6}$
}

\begin{abstract}
- Additional material is published online only. To view please visit the journal online (http://dx.doi.org/10.1136/ bjsports-2016-096618).
\end{abstract}

'Department of Orthopaedic Surgery, Horsens Hospital,

Horsens, Denmark

2Section for Sport Science, Department of Public Health Aarhus University, Aarhus, Denmark

${ }^{3}$ Department of Orthopaedic Surgery, Schulthess Clinic,

Zurich, Switzerland

${ }^{4}$ Department of Orthopaedic Surgery, Aarhus University Hospital, Aarhus, Denmark ${ }^{5}$ Department of Clinical Medicine, Centre of Research in Rehabilitation (CORIR), Aarhus University, Aarhus, Denmark ${ }^{6}$ Human Performance Lab, Schulthess Clinic, Zurich, Switzerland

Correspondence to Signe Kierkegaard, Department of Orthopaedic Surgery, Horsens Hospital, Horsens DK-8700, Denmark; signekierkegaard@ hotmail.com

Accepted 19 October 2016 Published Online First 14 November 2016

\author{
ABSTRACT \\ Aim To investigate pain, activities of daily living (ADL) \\ function, sport function, quality of life and satisfaction at \\ different time points after hip arthroscopy in patients \\ with femoroacetabular impingement (FAI). \\ Design Systematic review with meta-analysis. \\ Weighted mean differences between preoperative and \\ postoperative outcomes were calculated and used for \\ meta-analysis.
}

Data sources EMBASE, MEDLINE, SportsDiscus, CINAHL, Cochrane Library, and PEDro.

Eligibility criteria for selecting studies Studies that evaluated hip pain, ADL function, sport function and quality of life before and after hip arthroscopy and postoperative satisfaction in patients with symptomatic FAI.

Results Twenty-six studies (22 case series, 3 cohort studies, 1 randomised controlled trial (RCT)) were included in the systematic review and 19 in the metaanalysis. Clinically relevant pain and $\mathrm{ADL}$ function improvements were first reported between 3 and 6 months, and sport function improvements between 6 months and 1 year after surgery. It is not clear when quality of life improvements were first achieved. On average, residual mild pain and ADL and sport function scores lower than their healthy counterparts were reported by patients following surgery. Postoperative patient satisfaction ranged from $68 \%$ to $100 \%$.

Conclusions On average, patients reported earlier pain and $A D L$ function improvements, and slower sport function improvements after hip arthroscopy for FAl. However, average scores from patients indicate residual mild hip pain and/or hip function lower than their healthy counterparts after surgery. Owing to the current low level of evidence, future RCTs and cohort studies should investigate the effectiveness of hip arthroscopy in patients with FAI.

Trial registration number CRD42015019649.

\section{INTRODUCTION}

Patients with symptomatic femoroacetabular impingement (FAI) experience hip pain, functional limitations during activities of daily living (ADL) and sport and reduced quality of life. ${ }^{1}$ In addition, they are exposed to an increased risk of developing hip osteoarthritis (OA) and progressing to total hip arthroplasty (THA). ${ }^{2}$ Patients with FAI may be offered hip preservation surgery, either arthroscopically or open, to decrease hip pain, improve their functional performance and, in a long-term perspective, to possibly prevent or postpone the development of hip OA. ${ }^{3}$

In the past decade, the number of hip arthroscopies performed in the USA has continuously increased. ${ }^{4}$ Mostly low level of evidence case series with broad patient inclusion criteria indicate that the arthroscopic treatment of intra-articular pathologies and correction of bony deformities related to FAI seem to reduce hip pain and improve hip function, with the majority of patients being satisfied with the surgical outcome. ${ }^{5}$ However, to the best of our knowledge, no published study has compared hip arthroscopy with other non-surgical interventions to establish the true effectiveness of hip arthroscopy for the management of FAI. ${ }^{6} 7$ Currently, several matched cohort studies and randomised controlled trials (RCT), aimed at comparing hip arthroscopy with other interventions, are registered in international clinical research databases. Therefore, the existing knowledge on the effectiveness of hip arthroscopy in patients with FAI may be expanded in the coming years.

Some systematic reviews have already summarised the current knowledge on patient-reported outcomes after hip arthroscopy in patients with FAI. ${ }^{5-12}$ The large majority of studies included in previous systematic reviews reported hip arthroscopy outcomes with composite scores (eg, Harris Hip Score and Non-Arthritic Hip Scale). ${ }^{5-12}$ However, such scores do not enable evaluation of changes in specific domains, such as hip pain, hip function during ADL and sport, quality of life and satisfaction. In contrast, other scores used to evaluate hip arthroscopy outcome, such as the Hip Outcome Score (HOS) ${ }^{13}$ and the Copenhagen Hip and Groin Outcome Score (HAGOS), ${ }^{14}$ quantify improvements in specific domains by means of outcome subscores. Additionally, no systematic review to date has reported domain-specific outcomes at different time points after hip arthroscopy. Despite the methodological limitations of the available studies, knowledge about the timely recovery of the aforementioned specific domains is of particular interest for hip surgeons and therapists in order to provide specific and realistic postoperative expectations to patients with FAI undergoing hip arthroscopy.

The aim of this systematic review was to investigate hip pain, ADL function, sport function, quality of life and satisfaction reported by patients with FAI at different time points before and after hip arthroscopy. 


\section{METHODS}

\section{Study selection}

This systematic review was performed in accordance with the PRISMA statement. ${ }^{15}$ The study protocol was registered at the "International prospective register of systematic reviews" (PROSPERO) database (CRD42015019649). Electronic searches were performed by two authors (SK and ML-C) in the EMBASE, MEDLINE, SportsDiscus, CINAHL, Cochrane Library and PEDro databases to identify studies published before 20 September 2015. Key search terms were combined using three main filters: (1) Femoroacetabular/Hip, (2) Impingement and (3) Arthroscopy, and applying relevant $\mathrm{MeSH}$ terms. The specific search terms used for the different databases are shown in online supplementary table S1. Systematic reviews were additionally screened to detect eligible studies that were not identified by the electronic search. To be included in the systematic review, the studies had to satisfy the following criteria:

- Study design: Studies had to be RCTs, cohort studies, case-control studies or case series including $>10$ cases.

- Patients: Patients had to be $>16$ years old with a diagnosis of symptomatic FAI according to pain history, clinical and radiological evaluation. Patients without a diagnosis of FAI but treated with hip arthroscopy, patients with hip dysplasia, slipped capital femoral epiphysis or the Legg-Calve-Perthes disease, patients with previous hip arthroscopic or open surgery (revision surgery) and patients undergoing periacetabular osteotomy were all excluded.

- Intervention: Patients had to be treated with hip arthroscopic surgery, and the surgical procedure had to be described. Studies with combined arthroscopic and open surgical techniques were excluded.

- Outcomes: Preoperative and postoperative hip pain and/or hip function during ADL and sport and/or quality of life and/or postoperative satisfaction absolute scores had to be reported. Studies with composite scores were enrolled only if authors also separately reported the single subscores.

In order to assist the reviewers to evaluate the inclusion criteria, the following PICO (Population, Intervention, Comparison, Outcome) question ${ }^{16}$ was formulated: "How are the domains pain, ADL function, sport function, quality of life and satisfaction after surgery compared to before surgery, in patients with FAI who underwent primary hip arthroscopy?" No restrictions were imposed for language, publication date and publication status. All studies resulting from the electronic search were imported into a systematic review software (Covidence, Melbourne, Victoria, Australia) that automatically removed duplicates. SK and ML-C first independently screened titles and abstracts and then assessed study eligibility by reading the full text of the studies. Disagreement was resolved by consensus.

\section{Methodological quality assessment}

The methodological quality of the studies was independently assessed by two authors (SK and ML-C) using the tool developed by Yang et $a l,{ }^{17}$ with disagreement resolved by consensus. This tool evaluates (1) study aims and design, (2) description of the study treatment protocol, (3) description of the study methods and therapeutic/side effects, and (4) study conduction. Each criterion was rated either as 1 (if the criterion was met) or 0 (if criterion was not met). The total score was the sum of all satisfied criteria and ranged from 0 to $13(13=$ highest methodological quality). ${ }^{17}$ Studies with total scores $<5$ were considered to be of low methodological quality, 5-8 with moderate methodological quality and $>8$ with high methodological quality. ${ }^{17} 18$

\section{Data extraction}

Data were independently extracted by SK and ML-C with the exception of surgical procedure data, which were extracted by SK and BL. Disagreement was resolved by consensus. The extracted data included the country where the study was performed, study design, number of patients at recruitment and at final follow-up, number of patients who underwent revision surgery or THA, patient characteristics (age, gender), criteria for the diagnosis of FAI, included FAI types, presence and degree of coexisting hip joint disease, and description of the surgical procedure. Preoperative and postoperative hip pain, ADL function, sport function, quality of life scores and postoperative satisfaction scores were extracted. Postoperative scores were grouped by follow-up times: $<3$ months, 3 to $<6$ months, 6 months to $<1$ year, 1 to $<2$ years, 2 to $<3$ years, 3 to $<4$ years, 4 to $<5$ years and $\geq 5$ years. The scores, which were used to assess hip arthroscopy outcomes in the included studies, are listed in table 1 grouped by domain. All scores were converted to a 100-point scale, where 100 indicated the best possible score, except for visual analogue scale (VAS) and numeric rating scale (NRS) where 0 indicated no pain.

\section{Statistical analysis}

Percentage agreement and Cohen $\mathrm{k}$ statistics (mean and 95\% $\mathrm{CI}$ ) were calculated to provide an estimate of the level of agreement between raters when scoring the methodological quality of the included studies. Weighted mean scores were calculated for all scores at the different follow-up times adjusted to the number of patients. Weighted mean differences (WMD) were calculated for pain, ADL function, sport function and quality of life at the different follow-up times by subtracting the preoperative to the postoperative scores and adjusting to the number of patients. Positive WMD indicated a score improvement. The meta-analysis of WMD was performed with random effects meta-analysis. Hedges' g was applied adjusting for differences in sample size. Between-study variance and heterogeneity among studies were calculated. ${ }^{20}{ }^{21}$ Between-study variance was evaluated using $\chi^{2}$ tests and $\tau^{2}$. The degree of heterogeneity was interpreted as follows: $\mathrm{I}^{2}<30 \%$ 'might not be important', $30-75 \%$ 'moderate' and $>75 \%$ 'considerable'. ${ }^{20}$ Sensitivity analyses were performed analysing the WMDs of studies with high methodological quality only. Minimal important changes (MIC), which were calculated by previous studies in different patient

Table 1 Domain-specific outcome scores

\begin{tabular}{|c|c|}
\hline Domain & Outcome scores \\
\hline Pain & $\begin{array}{l}\text { VAS_pain } \\
\text { NRS-pain } \\
\text { HAGOS-pain }{ }^{14} \\
\text { HOOS-pain }{ }^{19}\end{array}$ \\
\hline ADL function & $\begin{array}{l}\text { HAGOS-function } \\
\text { HOS-ADL }{ }^{13} \\
\text { HOOS-function }\end{array}$ \\
\hline Sport function & $\begin{array}{l}\text { HAGOS-sport } \\
\text { HOS-sport } \\
\text { HOOS-sport }\end{array}$ \\
\hline Quality of life & $\begin{array}{l}\text { HAGOS-quality of life } \\
\text { HOOS-quality of life }\end{array}$ \\
\hline Satisfaction & $\begin{array}{l}0-100 \mathrm{~mm} \text { scale or } 1-10 \text { points } \\
\% \text { satisfaction }\end{array}$ \\
\hline
\end{tabular}

ADL, activity of daily living; HAGOS, Copenhagen Hip and Groin Outcome Score; HOOS, Hip Dysfunction and Osteoarthritis Outcome Score; HOS, Hip Outcome Score; NRS, numeric rating scale; VAS, visual analogue scale. 
populations (pain) ${ }^{22}$ and specifically in young hip patients (ADL function, sport function, quality of life), ${ }^{23}{ }^{24}$ were used to evaluate the clinical relevance of the calculated WMD. MIC was 30 points for pain assessed with VAS and NRS; ${ }^{22} 9$ points for pain and ADL function measured with HAGOS, HOOS, and HOS ADL; ${ }^{23} 2410$ points for sport function assessed with HAGOS and HOOS; ${ }^{23} 6$ points for sport function measured with HOS sport; ${ }^{24}$ and 11 points for hip-related quality of life measured with HAGOS and HOOS. ${ }^{23}$ The significance of WMD was defined by the lower bound of the WMD 95\% CI being higher than the respective MIC. The statistical analyses were performed with Stata 13 (StataCorp, College Station, Texas, USA). Significance level was set at $\mathrm{p}<0.05$.

\section{RESULTS}

\section{Study selection and methodological quality}

A total of 1949 studies were identified by the electronic search (figure 1). After duplicate removal and title and abstract screening, 253 full-text articles were evaluated for eligibility, of which 26 were included in the systematic review. A total of 19 studies reporting preoperative and postoperative pain and/or ADL function and/or sport function and/or quality of life scores were included into the meta-analysis. The remaining seven studies only reported postoperative satisfaction scores. These studies could only be qualitatively evaluated. The methodological quality of the single studies is reported in online supplementary table S2. Inter-rater agreement for methodological quality of the studies was $83 \%$ (Cohen's k: 0.34 (0.19 to 0.50$)$ ). Some studies reported scores of patient subgroups already included in previous studies. In these cases, studies with the highest number of patients and with the longest follow-up were used for analyses. ${ }^{25-28}$

\section{Study characteristics}

Individual study characteristics are presented in table 2. The 19 studies considered for meta-analysis ( 15 case series, 3 cohort studies, 1 RCT) included 2322 patients (42\% women) with a mean \pm SD age of $36 \pm 8$ years (range: $18-57$ ). The 3 cohort studies and 1 RCT considered for meta-analysis compared outcomes between 2 groups of patients who underwent different surgical techniques. A total of 175 patients $(7 \%)$ had revision surgery or THA, and 319 patients (14\%) were lost at follow-up. The 7 studies considered for the qualitative analysis (7 case series) included 494 patients (29\% women) with a mean \pm SD age of $37 \pm 14$ years (range: $22-65$ ). A total of 25 patients $(5 \%)$ had revision surgery or THA, and 8 patients (2\%) were lost at follow-up. The criteria for symptomatic FAI diagnosis generally included (i) hip pain and functional limitations, (ii) physical examinations and (iii) imaging (ie, radiographs, magnetic resonance images and/or CT scans) (see online supplementary table S3). A total of 19 studies included patients with all FAI types, 3 studies patients with cam FAI only, 2 studies patients with cam and mixed FAI, and 2 studies patients with pincer and mixed FAI. Patients presenting with different grades of hip articular cartilage lesions according to preoperative and/or intraoperative evaluations were included. Acetabulum labral lesions were addressed with labrum debridement or repair, articular cartilage lesions with chondroplasty or microfracture, and femoral and acetabular bony deformities with osteoplasty.

Preoperative and postoperative absolute scores for pain, ADL function, sport function and quality of life are reported in table 3 and postoperative satisfaction scores in online supplementary table S4. Preoperative and postoperative weighted mean scores are reported in figure 2.
Figure 1 Flow chart of the study selection process.
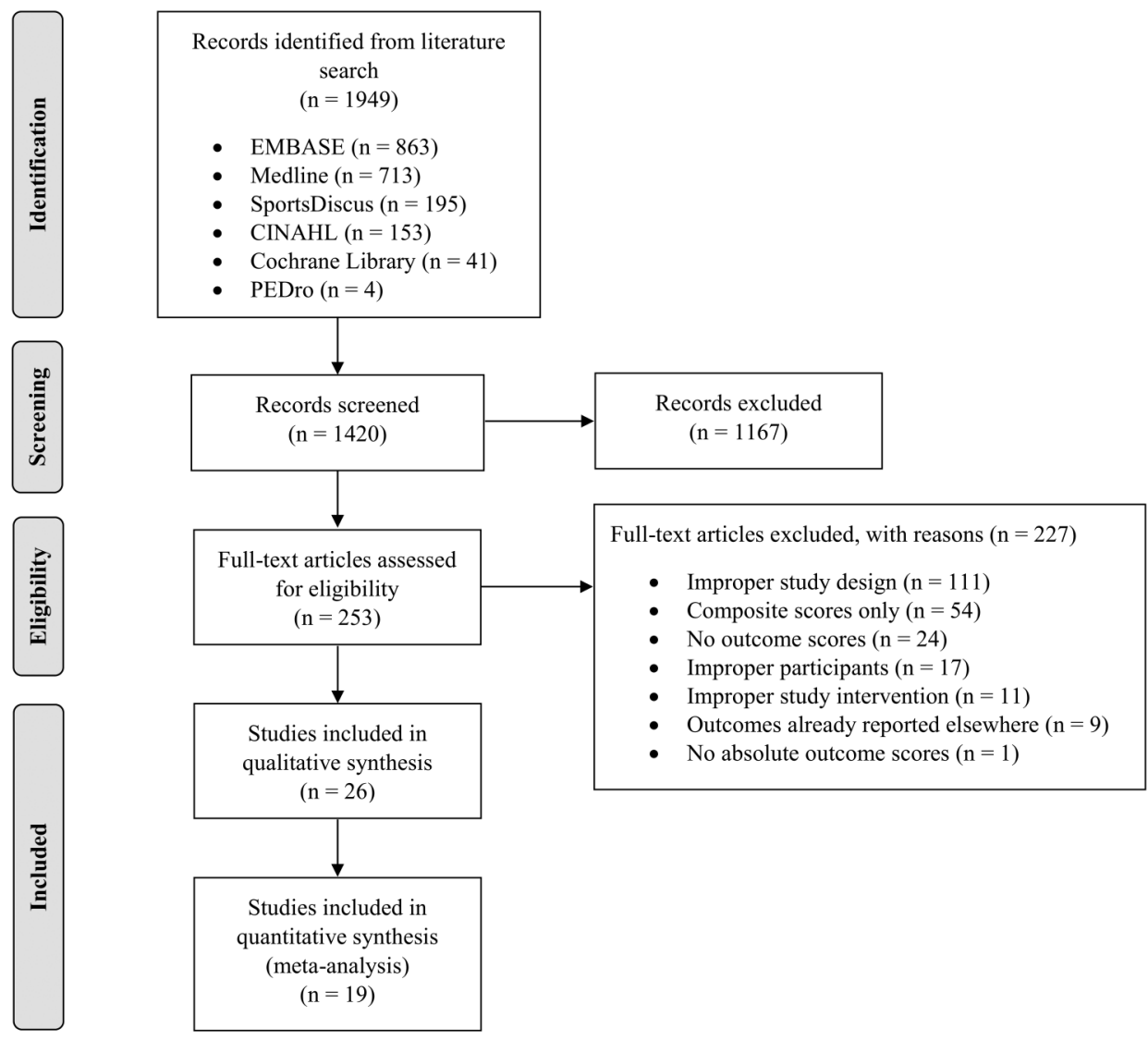
Table 2 Study characteristics

\begin{tabular}{|c|c|c|c|c|c|c|c|}
\hline \multirow[b]{2}{*}{ Study } & \multicolumn{5}{|c|}{ Study characteristics } & \multicolumn{2}{|c|}{ Patients' characteristics } \\
\hline & Country & Design & $\begin{array}{l}\text { Number of patients } \\
\text { at recruitment }\end{array}$ & $\begin{array}{l}\text { Number of } \\
\text { patients at final FU }\end{array}$ & $\begin{array}{l}\text { Number of } \\
\text { revisions/THA }\end{array}$ & $\begin{array}{l}\text { Mean age } \\
\text { (years) }\end{array}$ & $\begin{array}{l}\text { Gender } \\
\text { (\% female) }\end{array}$ \\
\hline Dippmann et al ${ }^{29}$ & Denmark & Case series & 92 & 87 & 5 & 38 & 63 \\
\hline Fabricant et $\left.a\right|^{30}$ & USA & Case series & 21 & 21 & 0 & 18 & 43 \\
\hline Frank et $a l^{31}$ & USA & Cohort study & 64 & 60 & 4 & 33 & 63 \\
\hline Gicquel et $a^{32}$ & France & Case series & 56 & 51 & 7 & 31 & 63 \\
\hline Horisberger et $a l^{25}$ & Switzerland & Case series & 88 & 79 & 9 & 41 & 32 \\
\hline Javed et $\left.a\right|^{\beta 3}$ & UK & Case series & 40 & 33 & 7 & 65 & 35 \\
\hline Krych et $a l^{34}$ & USA & RCT & 36 & 36 & 0 & 39 & 100 \\
\hline Larson et $a^{26}$ & USA & Cohort study & 96 & 90 & 6 & 30 & 40 \\
\hline Larson et $a \beta^{35}$ & USA & Case series & 220 & 220 & 0 & 31 & 52 \\
\hline Lerch et $a l^{\beta 6}$ & Germany & Case series & 40 & 40 & 0 & 39 & 0 \\
\hline Malviya et $a l^{37}$ & UK & Case series & 122 & 122 & NR & 35 & 39 \\
\hline Martinez et $\left.a\right|^{38}$ & Spain & Case series & 41 & 41 & 0 & 33 & 0 \\
\hline Nielsen et $a l^{39}$ & Denmark & Case series & 117 & 88 & 5 & 37 & 59 \\
\hline Palmer et a $\left.\right|^{40}$ & USA & Case series & 194 & 173 & 12 & 40 & 51 \\
\hline Park et $a l^{41}$ & Korea & Case series & 197 & 196 & 6 & 45 & 51 \\
\hline Philippon et $a l^{42}$ & USA & Case series & 122 & 102 & 10 & 41 & 55 \\
\hline Philippon et $a /^{43}$ & USA & Case series & 28 & 26 & 2 & 27 & 0 \\
\hline Philippon et $a l^{44}$ & USA & Case series & 153 & 122 & 31 & 57 & 53 \\
\hline Polat et $a l^{45}$ & Turkey & Case series & 42 & 41 & 1 & 35 & 40 \\
\hline Polesello et $\left.a\right|^{46}$ & Brazil & Case series & 27 & 24 & 3 & 35 & 12 \\
\hline Redmond et $a l^{28}$ & USA & Cohort study & 174 & 158 & 16 & 33 & 63 \\
\hline Singh et al ${ }^{47}$ & Australia & Case series & 24 & 24 & NR & 22 & 0 \\
\hline Skendzel et $a^{27}$ & USA & Case series & 559 & 314 & 117 & 37 & 38 \\
\hline Stahelin et $a l^{48}$ & Switzerland & Case series & 22 & 22 & 0 & 42 & 32 \\
\hline Thomee et al ${ }^{49}$ & Sweden & Case series & 502 & 360 & 0 & 37 & 33 \\
\hline Zingg et $a l^{50}$ & Switzerland & Case series & 23 & 23 & 0 & 28 & 22 \\
\hline
\end{tabular}

FU, follow-up; NR, not reported; THA, total hip arthroplasty.

\section{Quantitative analysis}

\section{Pain}

Pain WMD assessed using VAS was significantly larger than the respective MIC at 6 months to $<1$ year, 2 to $<3$ years and 4 to $<5$ years follow-ups, while pain WMD assessed using HAGOS/ HOOS questionnaires was significantly larger than the respective MIC at 3 to $<6$ months follow-up (table 4). Between-study variance and moderate to considerable heterogeneity $\left(\mathrm{I}^{2}: 56-\right.$ 97) was observed at all follow-ups, except at 4 to $<5$ years if pain was assessed using VAS and 3 to $<6$ months if pain was assessed using HAGOS/HOOS questionnaires. Following sensitivity analysis, no between-study variance was observed and heterogeneity was small to moderate $\left(\mathrm{I}^{2}: 0-38\right)$. The sensitivity analysis confirmed that pain WMD assessed using a VAS was significantly larger than the respective MIC at 6 months to $<1$ year and 2 to $<3$ years follow-ups (1 single study), and pain WMD assessed using HAGOS/HOOS questionnaires was significantly larger than the respective MIC at 3 to $<6$ months follow-up (1 single study).

\section{ADL function}

ADL function WMD was significantly larger than the respective MIC at 3 to $<6$ months, 6 months to $<1$ year ( 1 single study), 1 to $<2$ years and 2 to $<3$ years follow-ups, but not at 3 to $<4$ years and $\geq 5$ years follow-ups (table 4 ). Between-study variance and moderate to considerable heterogeneity $\left(\mathrm{I}^{2}: 64-85\right)$ were observed from 1 to $<2$ years to 3 to $<4$ years follow-ups. Following sensitivity analysis, no between-study variance was observed and heterogeneity was small to moderate $\left(\mathrm{I}^{2}: 0-30\right)$. In addition, ADL function WMD was significantly larger than the respective MIC at 3 to $<6$ months ( 1 single study), 6 months to $<1$ year ( 1 single study), 1 to $<2$ years and 2 to $<3$ years follow-ups.

\section{Sport function}

Sport function WMD was significantly larger than the respective MIC at 3 to $<6$ months, 6 months to $<1$-year (one single study), 1 to $<2$ years, 2 to $<3$ years, 3 to $<4$ years (one single study) and $\geq 5$ years follow-ups (one single study) (table 4 ). Small to considerable heterogeneity were overall observed $\left(\mathrm{I}^{2}\right.$ : 0-93) and between-study variance was significant at 2 to $<3$ years follow-up. Following sensitivity analysis, sport function WMD was significantly larger than the respective MIC at 6 months to $<1$ year ( 1 single study), 1 to $<2$ years and 2 to $<3$ years follow-ups. Small to considerable heterogeneity were overall observed $\left(\mathrm{I}^{2}: 23-80\right)$, and significant between-study variance was observed at 2 to $<3$ years follow-up.

Quality of life

Only 2 studies evaluated quality of life and only at 3 to $<6$ months follow-up. Quality of life WMD was significantly larger than the respective MIC at 3 to $<6$ months follow-up (table 4). No between-study variance and heterogeneity were observed. Following sensitivity analysis, clinically relevant quality of life improvement was not significant at 3 to $<6$ months follow-up (1 single study). 
Table 3 Hip pain, ADL function, sport function and quality of life preoperative and postoperative scores

\begin{tabular}{|c|c|c|c|c|c|c|c|}
\hline \multirow[b]{2}{*}{ Domain } & \multirow[b]{2}{*}{ Follow-up time } & \multirow[b]{2}{*}{ Study } & \multirow[b]{2}{*}{$\begin{array}{l}\text { Number of } \\
\text { patients }\end{array}$} & \multicolumn{4}{|c|}{ Score 0-100 } \\
\hline & & & & Score & $\begin{array}{l}\text { Preoperative } \\
\text { Mean } \pm S D\end{array}$ & $\begin{array}{l}\text { Postoperative } \\
\text { Mean } \pm \text { SD }\end{array}$ & $\begin{array}{l}\text { Difference } \\
\text { Mean }(95 \% \mathrm{Cl})\end{array}$ \\
\hline \multirow[t]{30}{*}{ Pain } & \multirow[t]{3}{*}{$<3$ mos } & Larson et $a l^{26}$ & 42 & VAS & $65 \pm 18$ & $28 \pm 20$ & 37 (29 to 45$)$ \\
\hline & & Larson et $a^{26}$ & 48 & VAS & $57 \pm 20$ & $24 \pm 18$ & 33 (25 to 41$)$ \\
\hline & & Zingg et $\left.a\right|^{50}$ & 23 & VAS & $34 \pm 25$ & $15 \pm 15$ & 19 (7 to 31$)$ \\
\hline & \multirow[t]{6}{*}{3 to $<6 \mathrm{mos}$} & Dippmann et a ${ }^{29}$ & 87 & VAS & $58 \pm 24$ & $30 \pm 25$ & 28 (21 to 35$)$ \\
\hline & & Larson et $a l^{26}$ & 42 & VAS & $65 \pm 18$ & $12 \pm 10$ & 53 (47 to 59 ) \\
\hline & & Larson et $a^{26}$ & 48 & VAS & $57 \pm 20$ & $13 \pm 9$ & 44 (38 to 50$)$ \\
\hline & & Lerch et $a l^{36}$ & 40 & HOOS & $53 \pm 18$ & $70 \pm 19$ & 17 (9 to 25$)$ \\
\hline & & Thomee et $a l^{49}$ & 502 & HAGOS & $55 \pm 19$ & $73 \pm 20$ & 18 (15 to 21$)$ \\
\hline & & Zingg et $a^{50}$ & 23 & VAS & $34 \pm 25$ & $13 \pm 18$ & 20 (8 to 33 ) \\
\hline & \multirow[t]{4}{*}{6 mos to $<1 \mathrm{yr}$} & Dippmann et $a l^{29}$ & 87 & VAS & $58 \pm 24$ & $23 \pm 25$ & 35 (28 to 43$)$ \\
\hline & & Larson et $a^{26}$ & 42 & VAS & $65 \pm 18$ & $12 \pm 10$ & $53(47$ to 60$)$ \\
\hline & & Larson et $a l^{26}$ & 48 & VAS & $57 \pm 20$ & $11 \pm 10$ & 46 (39 to 52 ) \\
\hline & & Stahelin et $a l^{48}$ & 22 & VAS & $58 \pm 21$ & $14 \pm 17$ & 44 (33 to 55$)$ \\
\hline & \multirow[t]{4}{*}{1 to $<2$ yrs } & Dippmann et a ${ }^{29}$ & 87 & VAS & $58 \pm 24$ & $28 \pm 25$ & 30 (23 to 37 ) \\
\hline & & Larson et $a l^{26}$ & 42 & VAS & $65 \pm 18$ & $12 \pm 16$ & 53 (46 to 61$)$ \\
\hline & & Larson et $a^{26}$ & 48 & VAS & $57 \pm 20$ & $6 \pm 8$ & 51 (45 to 57 ) \\
\hline & & Zingg et $a l^{50}$ & 23 & VAS & $34 \pm 25$ & $10 \pm 17$ & 23 (11 to 36$)$ \\
\hline & \multirow[t]{7}{*}{2 to $<3 \mathrm{yrs}$} & Horisberger et $\mathrm{al}^{25}$ & 79 & VAS & $55 \pm 20^{*}$ & $15 \pm 17^{*}$ & 40 (34 to 46 ) \\
\hline & & Larson et $a l^{26}$ & 42 & VAS & $65 \pm 18$ & $21 \pm 20$ & 45 (36 to 53$)$ \\
\hline & & Larson et $a^{26}$ & 48 & VAS & $57 \pm 20$ & $12 \pm 18$ & 45 (37 to 53 ) \\
\hline & & Larson et $a \beta^{35}$ & 220 & VAS & $63 \pm 20^{*}$ & $17 \pm 17^{*}$ & 46 (43 to 49 ) \\
\hline & & Polat et $a l^{45}$ & 42 & VAS & $68 \pm 20^{*}$ & $19 \pm 17^{*}$ & 49 (41 to 57 ) \\
\hline & & Redmond et $a l^{28}$ & 69 & VAS & $57 \pm 22$ & $26 \pm 25$ & 31 (23 to 39 ) \\
\hline & & Redmond et $a l^{28}$ & 89 & VAS & $63 \pm 19$ & $28 \pm 23$ & 35 (29 to 41$)$ \\
\hline & \multirow[t]{3}{*}{3 to $<4$ yrs } & Larson et $a l^{26}$ & 42 & VAS & $65 \pm 18$ & $18 \pm 22$ & 47 (39 to 56$)$ \\
\hline & & Larson et $a l^{26}$ & 48 & VAS & $57 \pm 20$ & $6 \pm 13$ & 51 (44 to 58$)$ \\
\hline & & Nielsen et $a l^{39}$ & 117 & NRS & $50 \pm 27$ & $37 \pm 29$ & 13 (5 to 21$)$ \\
\hline & \multirow[t]{3}{*}{4 to $<5$ yrs } & Larson et $a l^{26}$ & 42 & VAS & $65 \pm 18$ & $20 \pm 22$ & 45 (36 to 54$)$ \\
\hline & & Larson et $a^{26}$ & 48 & VAS & $57 \pm 20$ & $8 \pm 12$ & 49 (42 to 56$)$ \\
\hline & & Palmer et $\left.a\right|^{40}$ & 173 & VAS & $68 \pm 10$ & $27 \pm 22$ & 41 (37 to 45 ) \\
\hline \multirow[t]{19}{*}{ ADL function } & \multirow[t]{2}{*}{3 to $<6$ mos } & Lerch et $a l^{\beta 6}$ & 40 & HOOS & $56 \pm 19$ & $74 \pm 21$ & 18 (9 to 27 ) \\
\hline & & Thomee et $a l^{49}$ & 502 & HAGOS & $58 \pm 24$ & $75 \pm 22$ & 18 (15 to 21$)$ \\
\hline & \multirow[t]{2}{*}{6 mos to $<1 \mathrm{yr}$} & Frank et $\left.a\right|^{31}$ & 28 & HOS & $65 \pm 17$ & $84 \pm 13$ & 19 (11 to 27$)$ \\
\hline & & Frank et $a l^{31}$ & 32 & HOS & $66 \pm 16$ & $89 \pm 10$ & 23 (16 to 29$)$ \\
\hline & 1 to $<2 \mathrm{yrs}$ & Fabricant et $\left.a\right|^{30}$ & 21 & HOS & $77 \pm 19^{*}$ & $92 \pm 8^{*}$ & 15 (6 to 24$)$ \\
\hline & & Frank et $a l^{31}$ & 28 & HOS & $65 \pm 17$ & $86 \pm 10$ & 21 (14 to 29$)$ \\
\hline & & Frank et $a l^{31}$ & 32 & HOS & $66 \pm 16$ & $90 \pm 9$ & 24 (18 to 30$)$ \\
\hline & & Nielsen et $a l^{39}$ & 117 & HOS & $71 \pm 17$ & $85 \pm 17$ & 14 (9 to 18$)$ \\
\hline & 2 to $<3 \mathrm{yrs}$ & Frank et $\left.a\right|^{31}$ & 28 & HOS & $65 \pm 17$ & $91 \pm 8$ & 26 (19 to 33$)$ \\
\hline & & Frank et $a l^{\beta 1}$ & 32 & HOS & $66 \pm 16$ & $92 \pm 8$ & 26 (20 to 32 ) \\
\hline & & Krych et $a \beta^{34}$ & 18 & HOS & $68 \pm 19^{*}$ & $91 \pm 19^{*}$ & 23 (11 to 35$)$ \\
\hline & & Krych et al ${ }^{34}$ & 18 & HOS & $60 \pm 19^{*}$ & $81 \pm 19^{*}$ & 21 (9 to 33 ) \\
\hline & & Martinez et $a l^{38}$ & 41 & HOS & $65 \pm 15$ & $98 \pm 4$ & 33 (28 to 37 ) \\
\hline & & Philippon et $a /^{42}$ & 102 & HOS & $70 \pm 19$ & $88 \pm 17$ & 18 (13 to 23$)$ \\
\hline & & Redmond et $a l^{28}$ & 69 & HOS & $65 \pm 21$ & $87 \pm 17$ & 22 (16 to 28$)$ \\
\hline & & Redmond et $a l^{28}$ & 89 & HOS & $63 \pm 19$ & $86 \pm 16$ & 24 (18 to 29$)$ \\
\hline & 3 to $<4 \mathrm{yrs}$ & Philippon et $a l^{44}$ & 153 & HOS & $66 \pm 19$ & $87 \pm 19$ & 21 (16 to 26$)$ \\
\hline & & Nielsen et $a l^{39}$ & 117 & HOS & $71 \pm 17$ & $84 \pm 17$ & 12 (8 to 17$)$ \\
\hline & $\geq 5$ yrs & Skendzel et $a^{27}$ & 314 & HOS & $72 \pm 19^{*}$ & $82 \pm 19^{*}$ & 10 (7 to 12$)$ \\
\hline Sport function & 3 to $<6$ mos & Lerch et $a l^{36}$ & 40 & HOOS & $40 \pm 22$ & $57 \pm 27$ & 17 (6 to 28$)$ \\
\hline & & Thomee et $a l^{49}$ & 502 & HAGOS & $37 \pm 22$ & $57 \pm 26$ & 19 (16 to 22$)$ \\
\hline & $6 \mathrm{mos}$ to $<1 \mathrm{yr}$ & Frank et $a l^{\beta 1}$ & 28 & HOS & $39 \pm 24$ & $64 \pm 31$ & 24 (10 to 39$)$ \\
\hline & & Frank et $a l^{31}$ & 32 & HOS & $39 \pm 24$ & $78 \pm 16$ & 39 (29 to 49$)$ \\
\hline & 1 to $<2 \mathrm{yrs}$ & Fabricant et $a l^{30}$ & 20 & HOS & $49 \pm 23^{*}$ & $82 \pm 23^{*}$ & 33 (19 to 47$)$ \\
\hline & & Frank et $a l^{\beta 1}$ & 28 & HOS & $39 \pm 24$ & $73 \pm 15$ & 33 (23 to 44$)$ \\
\hline & & Frank et $a \beta^{31}$ & 32 & HOS & $39 \pm 24$ & $83 \pm 11$ & 43 (34 to 53 ) \\
\hline
\end{tabular}


Table 3 Continued

\begin{tabular}{|c|c|c|c|c|c|c|c|}
\hline \multirow[b]{2}{*}{ Domain } & \multirow[b]{2}{*}{ Follow-up time } & \multirow[b]{2}{*}{ Study } & \multirow[b]{2}{*}{$\begin{array}{l}\text { Number of } \\
\text { patients }\end{array}$} & \multicolumn{4}{|c|}{ Score 0-100 } \\
\hline & & & & Score & $\begin{array}{l}\text { Preoperative } \\
\text { Mean } \pm \text { SD }\end{array}$ & $\begin{array}{l}\text { Postoperative } \\
\text { Mean } \pm \text { SD }\end{array}$ & $\begin{array}{l}\text { Difference } \\
\text { Mean }(95 \% \mathrm{Cl})\end{array}$ \\
\hline & 2 to $<3$ yrs & Frank et $a l^{31}$ & 28 & HOS & $39 \pm 24$ & $84 \pm 10$ & 44 (35 to 54$)$ \\
\hline & & Frank et $a l^{31}$ & 32 & HOS & $39 \pm 24$ & $87 \pm 8$ & 48 (39 to 57 ) \\
\hline & & Krych et $a l^{34}$ & 18 & HOS & $48 \pm 23^{*}$ & $89 \pm 23^{*}$ & 41 (26 to 56$)$ \\
\hline & & Krych et $a l^{34}$ & 18 & HOS & $41 \pm 23^{*}$ & $76 \pm 23 *$ & $36(21$ to 51$)$ \\
\hline & & Martinez et $a \beta^{38}$ & 41 & HOS & $29 \pm 18$ & $95 \pm 6$ & 67 (61 to 73$)$ \\
\hline & & Philippon et $a l^{42}$ & 102 & HOS & $43 \pm 23$ & $69 \pm 23$ & 26 (20 to 32$)$ \\
\hline & & Redmond et $a l^{28}$ & 69 & HOS & $45 \pm 26$ & $75 \pm 28$ & 30 (21 to 39$)$ \\
\hline & & Redmond et $a l^{28}$ & 89 & HOS & $40 \pm 23$ & $74 \pm 25$ & 34 (27 to 41$)$ \\
\hline & 3 to $<4$ yrs & Philippon et $a{ }^{44}$ & 153 & HOS & $42 \pm 23$ & $72 \pm 23$ & 30 (24 to 36$)$ \\
\hline & $\geq 5$ yrs & Skendzel et $a l^{27}$ & 314 & HOS & $46 \pm 23 *$ & $77 \pm 23^{*}$ & 31 (27 to 34$)$ \\
\hline \multirow[t]{2}{*}{ Quality of life } & 3 to $<6 \mathrm{mos}$ & Lerch et $a \beta^{36}$ & 40 & HOOS & $26 \pm 12$ & $43 \pm 27$ & 17 (8 to 26$)$ \\
\hline & & Thomee et $a l^{49}$ & 502 & HAGOS & $30 \pm 18$ & $49 \pm 25$ & 19 (16 to 22$)$ \\
\hline
\end{tabular}

${ }^{*} \mathrm{SD}$ was imputed from mean of other studies.

ADL, activity of daily living; mos, months; yrs, years; Group a, b, within-study results of different patient groups; VAS, visual analogue scale; NRS, numeric rating scale; HAGOS, Copenhagen Hip and Groin Outcome Score; HOOS, Hip Dysfunction and Osteoarthritis Outcome Score; HOS, Hip Outcome Score.

Figure 2 Hip pain, ADL function, sport function and quality of life weighted mean scores. ADL, activities of daily living; HAGOS, Copenhagen Hip and Groin Outcome Score; HOOS, Hip Dysfunction and Osteoarthritis Outcome Score; VAS, visual analogue scale; NRS, numeric rating scale.

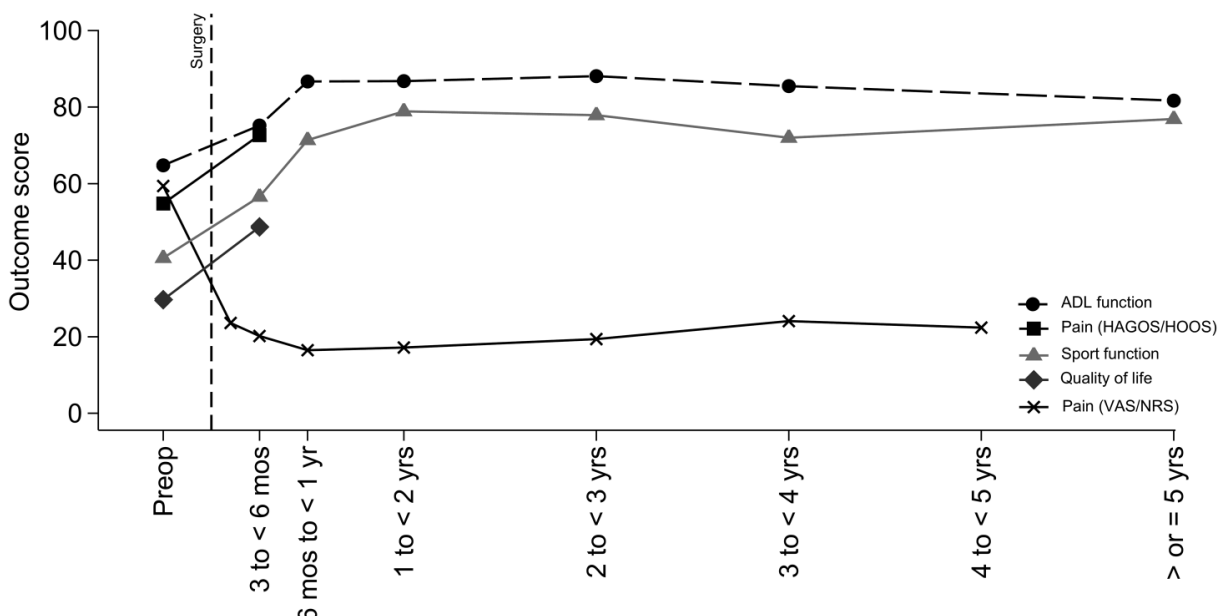

\section{Qualitative analysis}

Satisfaction

Patient satisfaction ranged from $68 \%$ to $100 \%$ when patients were asked if they were satisfied or dissatisfied with the hip arthroscopy outcome. Patient satisfaction ranged from 71 to 100 points when asked to indicate their satisfaction level either on a 0-100 or 1-10 scale. No clear pattern for increase or decrease in satisfaction scores was observed from $<3$ months after surgery to more than 5 years after surgery.

\section{DISCUSSION}

A total of 26 studies, predominantly reporting low level of evidence (22 case series, 3 cohort studies, 1 RCT), were included in the systematic review, which evaluated hip pain, ADL function, sport function, quality of life and satisfaction at different time points after hip arthroscopy in patients with FAI. The methodological quality of the included studies was moderate to high. Hip pain, ADL function and sport function improved after hip arthroscopy compared with preoperatively. The first clinically relevant hip pain decrease was observed at 3 to $<6$ months after surgery according to disease-specific questionnaires pain subscores, but at 6 months to $<1$ year after surgery according to generic pain scales. The first clinically relevant $\mathrm{ADL}$ and sport function improvements were observed at 3 to
$<6$ months and 6 months to $<1$ year after surgery, respectively. Pain, ADL and sport function improvements were evident up to 2 to $<3$ years after surgery.

To the best of our knowledge, this is the first study investigating patient-reported domain-specific outcomes at different follow-up time points after hip arthroscopy in patients with FAI This systematic review was performed using a reproducible search strategy and a validated tool for methodological quality evaluation. PRISMA guidelines were followed, with two reviewers involved during study and data selection. WMD's between preoperative and postoperative outcomes were included in the meta-analysis using MIC as cut-offs when evaluating the clinical relevance of the observed changes. ${ }^{13}$ This systematic review is limited by the generally low level of evidence of all included studies. Accordingly, our results need to be interpreted with caution. Since hip arthroscopy was not compared to an alternative treatment for FAI (eg, non-surgical treatment or sham surgery), our results are subjected to non-specific, placebo or natural history effects. In addition, large between- and within-study variability in patient inclusion criteria (eg, age, grade of articular cartilage damage) and surgical techniques (eg, acetabular labrum and cartilage treatment) were observed. Nevertheless, all the included studies evaluated patients who underwent hip arthroscopy for the treatment of symptomatic 
Table 4 Hip pain, ADL function, sport function and quality of life outcomes meta-analysis and sensitivity analysis

\begin{tabular}{|c|c|c|c|c|c|c|c|c|c|c|c|}
\hline \multirow[b]{2}{*}{ Domain } & \multirow[b]{2}{*}{ Follow-up time } & \multirow[b]{2}{*}{ Score } & \multirow[b]{2}{*}{ MIC } & \multicolumn{4}{|l|}{ All studies } & \multicolumn{4}{|l|}{ Sensitivity analysis } \\
\hline & & & & Studies included & WMD $(95 \% \mathrm{Cl})$ & $\tau^{2}$ & $1^{2}$ & Studies included & WMD $(95 \% \mathrm{CI})$ & $\tau^{2}$ & $1^{2}$ \\
\hline \multirow[t]{8}{*}{ Pain } & $<3$ mos & VAS & 30 & 2650 & $31(22$ to 40$)$ & $43^{*}$ & 67 & 50 & 19 (7 to 31$)$ & - & \\
\hline & 3 to $<6 \mathrm{mos}$ & VAS & 30 & 262950 & $37(24$ to 50$)$ & $167^{*}$ & 92 & 2950 & 26 (19 to 32$)$ & 1 & 4 \\
\hline & & HAGOS, HOOS & 9 & 3649 & $18(16$ to 21$)$ & 0 & 0 & 36 & 17 (9 to 25$)$ & - & \\
\hline & 6 mos to $<1$ year & VAS & 30 & 262948 & 45 (37 to 53 ) & $51 *$ & 78 & 2848 & 39 (30 to 47$)$ & 14 & 38 \\
\hline & 1 to $<2$ years & VAS & 30 & 262948 & 40 (27 to 54$)$ & $171 *$ & 92 & 2948 & $28(22$ to 35$)$ & 0 & 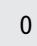 \\
\hline & 2 to $<3$ years & VAS & 30 & 2526283545 & 42 (37 to 46$)$ & $26^{*}$ & 72 & 25 & 40 (34 to 46$)$ & - & \\
\hline & 3 to $<4$ years & VAS, NRS & 30 & 2639 & $37(13$ to 50$)$ & $431^{*}$ & 97 & - & - & - & \\
\hline & 4 to $<5$ years & VAS & 30 & 2640 & $44(39$ to 50$)$ & 12 & 56 & - & - & - & \\
\hline \multirow[t]{6}{*}{ ADL function } & 3 to $<6 \mathrm{mos}$ & HAGOS, HOOS & 9 & 3649 & 18 (15 to 21$)$ & 0 & 0 & 36 & 18 (9 to 27$)$ & - & \\
\hline & 6 mos to $<1$ year & HOS & 9 & $31 \sim$ & 22 (17 to 27$)$ & 0 & 0 & $31 \sim$ & 22 (17 to 27$)$ & 0 & 0 \\
\hline & 1 to $<2$ years & HOS & 9 & 303139 & 18 (13 to 24$)$ & $19^{*}$ & 64 & 3031 & 21 (16 to 26$)$ & 5 & 26 \\
\hline & 2 to $<3$ years & HOS & 9 & 2831343842 & 24 (20 to 28$)$ & $19^{*}$ & 65 & 313442 & 23 (19 to 27$)$ & 6 & 30 \\
\hline & 3 to $<4$ years & HOS & 9 & 3944 & 17 (8 to 25$)$ & $32^{*}$ & 85 & - & - & - & \\
\hline & $\geq 5$ years & HOS & 9 & 27 & $10(7$ to 13$)$ & - & & - & - & - & \\
\hline \multirow[t]{6}{*}{ Sport function } & 3 to $<6 \mathrm{mos}$ & HAGOS, HOOS & 10 & 3649 & $19(16$ to 22$)$ & 0 & 0 & 36 & 17 (6 to 28$)$ & - & \\
\hline & 6 mos to $<1$ year & HOS & 6 & $31 \sim$ & 33 (19 to 47$)$ & 64 & 61 & $31 \sim$ & 33 (19 to 47 ) & 64 & 61 \\
\hline & 1 to $<2$ years & HOS & 6 & 3031 & 38 (30 to 45$)$ & 9 & 23 & 3031 & 38 (30 to 45 ) & 9 & 23 \\
\hline & 2 to $<3$ years & HOS & 6 & 2831343842 & 41 (29 to 53$)$ & 261 * & 93 & 313442 & 39 (29 to 49$)$ & $100 *$ & 80 \\
\hline & 3 to $<4$ years & HOS & 6 & 44 & $30(24$ to 36$)$ & - & & - & - & - & \\
\hline & $\geq 5$ years & HOS & 6 & 27 & 31 (27 to 34$)$ & - & & - & - & - & \\
\hline Quality of life & 3 to $<6 \mathrm{mos}$ & HAGOS, HOOS & 11 & 3649 & $19(16$ to 22$)$ & 0 & 0 & 36 & 17 (8 to 26$)$ & - & \\
\hline
\end{tabular}

HAGOS, Copenhagen Hip and Groin Outcome Score; HOOS, Hip dysfunction and Osteoarthritis Outcome Score; HOS, Hip Outcome Score; I2, degree of heterogeneity; MIC, minimal important change; NRS, numeric rating scale; $\tau^{2}$, between-study variance; VAS, visual analogue scale; WMD, weighted mean difference.

$\sim$ Only one study but with two groups; therefore, analysis of $\tau^{2}$ and $I^{2}$ was possible.

${ }^{*}$ Between-study variance significant at $\mathrm{p}<0.05$.

FAI. Last, most of the outcomes presented at the different follow-ups did not include the data of patients who underwent revision surgery or THA. Accordingly, this may have potentially underestimated pain and overestimated ADL and sport function as well as quality of life and satisfaction of patients at followups. Hence, the results of this review should be interpreted also considering the reported rates of revision surgery and THA conversion ( $7 \%$ in the 26 studies), and that $12 \%$ of the patients were lost to follow-up.

The strongest and most consistent findings from our sensitivity analysis indicated that the first clinically relevant pain reduction was achieved between 3 and $<6$ months after surgery according to studies that assessed pain subscores using diseasespecific questionnaires (ie, HAGOS pain and HOOS pain). In contrast, the first clinically significant pain reduction using general unidimensional pain scales (ie, VAS and NRS) was observed between 6 months and $<1$ year after surgery. Disease-specific questionnaires were developed in order to assess pain frequency and intensity under standard conditions and time intervals. In our meta-analysis, disease-specific questionnaires were used to evaluate pain by only 2 studies and at a single time point ( 3 to $<6$ months), while general unidimensional scales were otherwise used. Disease-specific questionnaires are generally preferred to unidimensional scales to evaluate outcomes following hip arthroscopy for FAI. ${ }^{5}{ }^{8-12}$ Nevertheless, studies that used disease-specific questionnaires to assess pain at follow-ups longer than 6 months could not be included in our meta-analysis, since they provided composite scores. In contrast, general unidimensional scales only allow measurement of pain intensity ${ }^{22}$ under conditions and time intervals arbitrarily defined by the investigators. As an example, some studies might investigate pain at rest during the past 24 hours, while others might ask about pain during activity over the past month. This may lead to large variability of pain levels, and it reduces the ability of general unidimensional scales to detect significant pain changes when they actually occur. For these reasons, we decided to interpret the first clinically relevant pain decrease according to disease-specific questionnaire pain subscores, that is, between 3 and $<6$ months, even if they were used by only 2 studies included in the meta-analysis.

Of note, some pain (on average around 20 points on a $0-100$ scale, where 0 points correspond to no pain at all) was reported by patients after hip arthroscopy until the last available follow-up ( 4 to $<5$ years). This suggests that a number of patients might present with residual pain after hip arthroscopy. The origin of postoperative residual pain may be intra-articular (eg, scar tissue, remaining impingement problems, cartilage lesions), extra-articular (eg, muscles, other soft tissues) or a combination of these. Persisting muscle strength impairments after surgery have been demonstrated in patients with FAI, ${ }^{51} 52$ and hip muscle imbalance has been linked to groin pain in some athletic populations. ${ }^{53}$ Hence, residual pain could be related to persistent postoperative hip muscle impairments in patients with FAI. This relation between hip pain and muscle function after hip arthroscopy is worth to be investigated by future studies.

Improvements in ADL function were smaller (range: 10-24 points) compared to those observed for sport function (range: $19-41$ points). This might be related to the relatively high ADL scores reported preoperatively, ${ }^{30} 38$ reflecting less difficulties with ADL than during sport activities. There appears to be a larger window for improvement in sport than ADL function following surgery. ADL, sport function and quality of life all showed the first clinical relevant improvement between 3 and $<6$ months after surgery, if all the included studies were considered. Of note, however, high-quality studies only confirmed these results for ADL function. In contrast, the first clinically 
relevant improvement for sport function could be only confirmed between 6 months and 1 year after surgery, and quality of life improvement could not be confirmed at any later follow-up. The slow recovery of sport function may be related to the failure of increasing the quality of life of patients early after surgery. Indeed, it has been reported that the ability to return to sport is-together with pain reduction-the main postoperative expectation of patients with $\mathrm{FAI}^{54}{ }^{54}$ Therefore, the inability of patients to regain their sport function in the first months after surgery may substantially and negatively influence their early postoperative quality of life.

Our analyses showed that improvements in ADL and sport function are seen at all time points up to 2 to $<3$ years after hip arthroscopy based on high-quality studies (table 4). Only one study of moderate quality showed clinically relevant sport function improvements compared with preoperatively at $>5$ years after surgery. ${ }^{27}$ These results need, however, to be confirmed by high-quality studies. Regardless of follow-up time, a considerable number of studies did not report postoperative hip function scores comparable to healthy controls, neither during ADL ( $<90$ vs $99-100$, respectively) nor during sport ( $<80$ vs $98-$ 100 , respectively) (figure 2). ${ }^{23}$ These findings are in line with those reported by patients with hip dysplasia, who also underwent hip preservation surgery. ${ }^{55}$

The dissatisfaction rates reported by patients after hip arthroscopy ranged between $0 \%$ and $32 \%$. This dissatisfaction rate corresponds with those reported by previous studies. ${ }^{56}$ The rate of dissatisfaction may, at least in part, be explained by residual hip pain and/or impaired hip function during ADL and sport reported, on average, after surgery. In addition, the fact that patients with progressed hip joint degeneration (eg, Tönnis grade $\geq 2$ ) at the time of hip arthroscopy were included in the evaluated studies may explain the residual pain and lower hip function compared with healthy counterparts reported by a number of patients after surgery. Indeed, limited articular joint space at the time of hip arthroscopy, indicating progressed hip OA, has been associated with postoperative low ADL and sport function outcomes, high THA conversion rate and low satisfaction of patients at 2 to $<3$ years, ${ }^{42} 3$ to $<4$ years ${ }^{44}$ and $\geq 5$ years follow-ups. ${ }^{27}$ Future high-quality studies are needed to investigate hip pain, ADL function and sport function improvements after hip arthroscopy in patients with FAI at follow-ups longer than 3 years. In addition, future research should investigate the effectiveness of hip arthroscopy in patients with FAI in improving pain, ADL and sport function in RCTs or cohort studies, which compare hip arthroscopy to non-surgical treatments for the management of symptomatic FAI.

\section{CONCLUSION}

Studies with low level of evidence (mostly case series) and broad inclusion criteria evaluated hip pain, ADL function, sport function, quality of life and satisfaction at different time points after hip arthroscopy in patients with FAI. On average, patients with symptomatic FAI experience hip pain reduction and ADL function improvement at 3 to $<6$ months after hip arthroscopy, and improvements in sport function at 6 months to $<1$ year postoperatively. Compared with preoperatively, reduced hip pain and improved ADL and sport function seem to be maintained up to 2 to $<3$ years after hip arthroscopy. More than two-thirds of the patients are satisfied after surgery. Nevertheless, average scores from patients indicate residual mild hip pain and/or ADL and sport function lower than their healthy counterparts after hip arthroscopy. Owing to the current low level of evidence, future RCTs and cohort studies should investigate the effectiveness of hip arthroscopy in patients with FAI.

\section{What is already known?}

- Patients with symptomatic femoroacetabular impingement (FAI) experience hip pain, as well as decreased activities of daily living (ADL) and sport function.

- Hip arthroscopy seems to reduce hip pain and improve ADL and sport function mostly based on low level of evidence case series, but the improvements at different time points are not known.

\section{What are the findings?}

- In patients with FAl, hip pain reduction and ADL function improvements may be achieved between 3 and 6 months after surgery, while sport function improvements occurs between 6 months and 1 year after hip arthroscopy.

- Hip pain, $A D L$ and sport function improvements are evident at least up to 3 years after hip arthroscopy in patients with FAl.

- Average scores from patients indicate residual mild hip pain and/or hip function during ADL and sport lower than their healthy counterparts after hip arthroscopy.

Contributors All authors helped design the study. SK and ML-C conducted literature search, data selection, quality assessment and data extraction (BL helped with surgical data). SK wrote the initial draft of the manuscript. All authors contributed the final draft and approved the manuscript before submission.

Competing interests None declared.

Provenance and peer review Not commissioned; externally peer reviewed.

\section{REFERENCES}

1 Kemp JL, Makdissi M, Schache AG, et al. Hip chondropathy at arthroscopy: prevalence and relationship to labral pathology, femoroacetabular impingement and patient-reported outcomes. British journal of sports medicine 2014;48:1102-7.

2 Agricola R, Heijboer MP, Bierma-Zeinstra SM, et al. Cam impingement causes osteoarthritis of the hip: a nationwide prospective cohort study (CHECK). Annals of the rheumatic diseases 2013;72:918-23.

3 Bedi A, Kelly BT. Femoroacetabular impingement. The Journal of bone and joint surgery. American volume 2013;95:82-92.

4 Bozic KJ, Chan V, Valone FH, et al. Trends in hip arthroscopy utilization in the United States. The Journal of arthroplasty 2013;28:140-3.

5 Harris JD, Erickson BJ, Bush-Joseph CA, et al. Treatment of femoroacetabular impingement: a systematic review. Curr Rev Musculoskelet Med 2013;6:207-18.

6 Wall PD, Brown JS, Parsons N, et al. Surgery for treating hip impingement (femoroacetabular impingement). Cochrane database of systematic reviews (Online) 2014;9:CD010796.

7 Kemp JL, Crossley KM, Roos EM, et al. What fooled us in the knee may trip us up in the hip: lessons from arthroscopy. British journal of sports medicine 2014:48:1200-1.

8 Baldwin KD, Harrison RA, Namdari S, et al. Outcomes of hip arthroscopy for treatment of femoroacetabular impingement: A systematic review. Current Orthopaedic Practice 2009;20:669-73.

9 Matsuda DK, Carlisle JC, Arthurs SC, et al. Comparative systematic review of the open dislocation, mini-open, and arthroscopic surgeries for femoroacetabular impingement. Arthroscopy: the journal of arthroscopic \& related surgery: official publication of the Arthroscopy Association of North America and the International Arthroscopy Association 2011;27:252-69.

10 Hetaimish BM, Khan M, Crouch S, et al. Consistency of reported outcomes after arthroscopic management of femoroacetabular impingement. Arthroscopy: the journal of arthroscopic \& related surgery: official publication of the Arthroscopy Association of North America and the International Arthroscopy Association 2013;29:780-7. 
11 Gillespie JA, Patil SR, Meek RD. Clinical outcome scores for arthroscopic femoral osteochondroplasty in femoroacetabular impingement: a quantitative systematic review. Scott Med J 2015;60:13-22.

12 Ayeni OR, Adamich J, Farrokhyar F, et al. Surgical management of labral tears during femoroacetabular impingement surgery: a systematic review. Knee surgery, sports traumatology, arthroscopy: official journal of the ESSKA 2014;22:756-62.

13 Martin RL, Kelly BT, Philippon MJ. Evidence of validity for the hip outcome score. Arthroscopy: the journal of arthroscopic \& related surgery: official publication of the Arthroscopy Association of North America and the International Arthroscopy Association 2006;22:1304-11.

14 Thorborg K, Holmich P, Christensen R, et al. The Copenhagen Hip and Groin Outcome Score (HAGOS): development and validation according to the COSMIN checklist. British journal of sports medicine 2011;45:478-91.

15 Liberati A, Altman DG, Tetzlaff J, et al. The PRISMA statement for reporting systematic reviews and meta-analyses of studies that evaluate healthcare interventions: explanation and elaboration. BMJ 2009;339:b2700.

16 Guyatt GH, Oxman AD, Kunz R, et al. GRADE guidelines: 2. Framing the question and deciding on important outcomes. Journal of clinical epidemiology 2011;64:395-400.

17 Yang AW, Li CG, Da Costa C, et al. Assessing quality of case series studies: development and validation of an instrument by herbal medicine CAM researchers. Journal of alternative and complementary medicine (New York, N.Y.) 2009;15:513-22.

18 Casartelli NC, Leunig M, Maffiuletti NA, et al. Return to sport after hip surgery for femoroacetabular impingement: a systematic review. British journal of sports medicine 2015:49:819-24.

19 Klassbo M, Larsson E, Mannevik E. Hip disability and osteoarthritis outcome score. An extension of the Western Ontario and McMaster Universities Osteoarthritis Index. Scandinavian journal of rheumatology 2003;32:46-51.

20 Higgins JP, Thompson SG. Quantifying heterogeneity in a meta-analysis. Statistics in medicine 2002;21:1539-58

21 Higgins JP, Thompson SG, Deeks JJ, et al. Measuring inconsistency in meta-analyses. BMJ 2003;327:557-60.

22 Hawker GA, Mian S, Kendzerska T, et al. Measures of adult pain: Visual Analog Scale for Pain (VAS Pain), Numeric Rating Scale for Pain (NRS Pain), McGill Pain Questionnaire (MPQ), Short-Form McGill Pain Questionnaire (SF-MPQ), Chronic Pain Grade Scale (CPGS), Short Form-36 Bodily Pain Scale (SF-36 BPS), and Measure of Intermittent and Constant Osteoarthritis Pain (ICOAP). Arthritis care \& research 2011:63:S240-52.

23 Kemp JL, Collins NJ, Roos EM, et al. Psychometric properties of patient-reported outcome measures for hip arthroscopic surgery. The American journal of sports medicine 2013;41:2065-73.

24 Martin RL, Philippon MJ. Evidence of reliability and responsiveness for the hip outcome score. Arthroscopy: the journal of arthroscopic \& related surgery: official publication of the Arthroscopy Association of North America and the International Arthroscopy Association 2008;24:676-82.

25 Horisberger M, Brunner A, Herzog RF. Arthroscopic treatment of femoroacetabular impingement of the hip: a new technique to access the joint. Clinical orthopaedics and related research 2010;468:182-90.

26 Larson CM, Giveans MR, Stone RM. Arthroscopic debridement versus refixation of the acetabular labrum associated with femoroacetabular impingement: mean 3.5-year follow-up. The American journal of sports medicine 2012;40:1015-21.

27 Skendzel JG, Philippon MJ, Briggs KK, et al. The effect of joint space on midterm outcomes after arthroscopic hip surgery for femoroacetabular impingement. The American journal of sports medicine 2014:42:1127-33.

28 Redmond JM, El Bitar YF, Gupta A, et al. Arthroscopic acetabuloplasty and labral refixation without labral detachment. The American journal of sports medicine 2015;43:105-12

29 Dippmann C, Thorborg K, Kraemer O, et al. Hip arthroscopy with labral repair for femoroacetabular impingement: short-term outcomes. Knee surgery, sports traumatology, arthroscopy: official journal of the ESSKA 2014;22:744-9.

30 Fabricant PD, Heyworth BE, Kelly BT. Hip arthroscopy improves symptoms associated with FAI in selected adolescent athletes. Clinical orthopaedics and related research 2012:470:261-9.

31 Frank RM, Lee S, Bush-Joseph CA, et al. Improved outcomes after hip arthroscopic surgery in patients undergoing T-capsulotomy with complete repair versus partial repair for femoroacetabular impingement: a comparative matched-pair analysis The American journal of sports medicine 2014:42:2634-42.

32 Gicquel T, Gedouin JE, Krantz N, et al. Function and osteoarthritis progression after arthroscopic treatment of femoro-acetabular impingement: a prospective study after a mean follow-up of $4.6(4.2-5.5)$ years. Orthopaedics \& traumatology, surgery \& research: OTSR 2014;100:651-6.

33 Javed A, O'Donnell JM. Arthroscopic femoral osteochondroplasty for cam femoroacetabular impingement in patients over 60 years of age. Journal of Bone and Joint Surgery - Series B 2011:93 B:326-31.

34 Krych AJ, Thompson M, Knutson Z, et al. Arthroscopic labral repair versus selective labral debridement in female patients with femoroacetabular impingement: a prospective randomized study. Arthroscopy: the journal of arthroscopic \& related surgery: official publication of the Arthroscopy Association of North America and the International Arthroscopy Association 2013;29:46-53.

35 Larson CM, Giveans MR, Samuelson KM, et al. Arthroscopic Hip Revision Surgery for Residual Femoroacetabular Impingement (FAI): Surgical Outcomes Compared With a Matched Cohort After Primary Arthroscopic FAI Correction. The American journal of sports medicine 2014;42:1785-90.

36 Lerch S, Kasperczyk A, Warnecke J, et al. Evaluation of Cam-type femoroacetabular impingement by ultrasound. International orthopaedics 2013:37:783-8.

37 Malviya A, Stafford GH, Villar RN. Is hip arthroscopy for femoroacetabular impingement only for athletes? British journal of sports medicine 2012:46:1016-18.

38 Martinez JM, Morales-Santias M, Bustamante S et al. Hip arthroscopy in males younger than 40 with femoroacetabular impingement: short-term outcomes. Revista espanola de cirugia ortopedica y traumatologia 2014;58:343-50.

39 Nielsen TG, Miller LL, Lund B, et al. Outcome of arthroscopic treatment for symptomatic femoroacetabular impingement. BMC musculoskeletal disorders 2014; 15:394

40 Palmer DH, Ganesh V, Comfort T, et al. Midterm outcomes in patients with cam femoroacetabular impingement treated arthroscopically. Arthroscopy: the journal of arthroscopic \& related surgery: official publication of the Arthroscopy Association of North America and the International Arthroscopy Association 2012;28:1671-81.

41 Park MS, Yoon SJ, Kim YJ, et al. Hip arthroscopy for femoroacetabular impingement: the changing nature and severity of associated complications over time. Arthroscopy: the journal of arthroscopic \& related surgery: official publication of the Arthroscopy Association of North America and the International Arthroscopy Association 2014:30:957-63.

42 Philippon MJ, Briggs KK, Yen YM, et al. Outcomes following hip arthroscopy for femoroacetabular impingement with associated chondrolabral dysfunction: minimum two-year follow-up. The Journal of bone and joint surgery. British volume 2009:91:16-23.

43 Philippon MJ, Weiss DR, Kuppersmith DA, et al. Arthroscopic labral repair and treatment of femoroacetabular impingement in professional hockey players. The American journal of sports medicine 2009:38:99-104.

44 Philippon MJ, Schroder ESBG, Briggs KK. Hip arthroscopy for femoroacetabular impingement in patients aged 50 years or older. Arthroscopy: the journal of arthroscopic \& related surgery: official publication of the Arthroscopy Association of North America and the International Arthroscopy Association 2012;28:59-65.

45 Polat G, Dikmen G, Erdil M, et al. Arthroscopic treatment of femoroacetabular impingement: early outcomes. Acta Orthop Traumatol Turc 2013;47:311-7.

46 Polesello GC, Lima FR, Guimaraes RP, et al. Arthroscopic treatment of femoroacetabular impingement: Minimum five-year follow-up. HIP International 2014; $24: 381-86$

47 Singh PJ, O'Donnell JM. The Outcome of Hip Arthroscopy in Australian Football League Players: A Review of 27 Hips. Arthroscopy - Journal of Arthroscopic and Related Surgery 2010;26:743-49.

48 Stahelin L, Stahelin T, Jolles BM, et al. Arthroscopic offset restoration in femoroacetabular cam impingement: accuracy and early clinical outcome. Arthroscopy: the journal of arthroscopic \& related surgery: official publication of the Arthroscopy Association of North America and the International Arthroscopy Association 2008;24:51-57.

49 Thomee R, Jonasson P, Thorborg K, et al. Cross-cultural adaptation to Swedish and validation of the Copenhagen Hip and Groin Outcome Score (HAGOS) for pain, symptoms and physical function in patients with hip and groin disability due to femoro-acetabular impingement. Knee surgery, sports traumatology, arthroscopy: official journal of the ESSKA 2014:22:835-42.

50 Zingg PO, Ulbrich EJ, Buehler TC, et al. Surgical hip dislocation versus hip arthroscopy for femoroacetabular impingement: clinical and morphological short-term results. Archives of orthopaedic and trauma surgery 2013;133:69-79.

51 Casartelli NC, Maffiuletti NA, Item-Glatthorn JF, Impellizzeri FM, Leunig M. Hip muscle strength recovery after hip arthroscopy in a series of patients with symptomatic femoroacetabular impingement. Hip international: the journal of clinical and experimental research on hip pathology and therapy 2014;24:387-93.

52 Freke MD, Kemp J, Svege I, et al. Physical impairments in symptomatic femoroacetabular impingement: a systematic review of the evidence. British journal of sports medicine 2016;50:1180.

53 Belhaj K, Meftah S, Mahir L, et al. Isokinetic imbalance of adductor-abductor hip muscles in professional soccer players with chronic adductor-related groin pain. European journal of sport science 2016:1-6.

54 Mannion AF, Impellizzeri FM, Naal FD, et al. Fulfilment of patient-rated expectation predicts the outcome of surgery for femoroacetabular impingement. Osteoarthritis and Cartilage 2013;21:44-50.

55 Birch S, Liljensoe A, Hartig-Andreasen C, Soballe K, et al. No correlations between radiological angles and self-assessed quality of life in patients with hip dysplasia at 2-13 years of follow-up after periacetabular osteotomy. Acta radiologica (Stockholm, Sweden: 1987) 2015:56:196-203.

$56 \mathrm{Ng} \mathrm{VY}$, Arora N, Best TM, et al. Efficacy of surgery for femoroacetabular impingement: a systematic review. The American journal of sports medicine 2010;38:2337-45. 